\title{
Developing Polycation-Clay Sorbents for Efficient Filtration of Diclofenac: Effect of Dissolved Organic Matter and Comparison to Activated Carbon
}

\author{
Hagay Kohay, Avital Izbitski, and Yael G. Mishael* \\ Department of Soil and Water Science, The Robert H. Smith Faculty of Agriculture, Food and Environment, Hebrew University of \\ Jerusalem, Rehovot 76100, Israel
}

\section{Supporting Information}

\begin{abstract}
The presence of nanoconcentrations of persistent pharmaceuticals in treated wastewater effluent and in surface water has been frequently reported. A novel organic-inorganic hybrid sorbent based on adsorbing quarternized poly vinylpyridinium-co-styrene (QPVPcS) to montmorillonite (MMT) was designed for the removal of the anionic micropollutants. QPVPcS-clay composites were characterized by X-ray diffraction, FTIR, thermal gravimetric analysis, Zeta potential and element analysis. Based on these measurements polymer-clay micro- and nanostructures, as a function of polymer loading, were suggested. The affinity of the anionic pharmaceutical, diclofenac (DCF), to the composite was high and did not decrease dramatically with an increase of ionic strength, indicating that the interactions are not only electrostatic. The presence of humic acid (HA) did not hinder DCF removal by the composite; whereas, its filtration by granulated activated carbon (GAC) was compromised in the presence of HA. The kinetics and adsorption at equilibrium of DCF to the composite and to GAC were measured and modeled by the time dependent Langmuir equation. The adsorption of DCF to the composite was significantly faster than to GAC. Accordingly, the filtration of micro- and nanoconcentrations of DCF by composite columns, in the presence of HA, was more efficient than by GAC columns.
\end{abstract}

\section{INTRODUCTION}

The presence of micro- and nanoconcentrations of pharmaceuticals in aquatic environments has drawn significant attention in the past decades. ${ }^{1-3}$ Reviews on the efficiency of removing pharmaceuticals by various technologies indicate that many of these compounds are resistant to the degradation and removal processes and therefore are present in the treated effluent. $^{4,5}$ Reusing the effluent for crop irrigation or discharging it to surface waters has raised environmental and health concerns which are currently investigated. ${ }^{6-8}$

One of the evasive pharmaceuticals which is frequently detected in treated effluent is diclofenac (DCF), a nonsteroidal anti-inflammatory drug. DCF has a relatively high water solubility due to its low $\mathrm{p} K_{\mathrm{a}}=4.15$. In treated wastewater effluent concentrations reached up to $2.5 \mu \mathrm{g} / \mathrm{L}^{9,10}$ and in surface water the detected concentrations were lower than 500 ng/L. ${ }^{3,11-13}$ The harmful effect of DCF at environmental concentrations on marine animals has been reported, ${ }^{14-20}$ and DCF was recently included in the European Union Priority Substances Directive watch list. ${ }^{9}$

The detection of DCF in treated wastewater effluent and in surface waters is mainly due to its low sedimentation ${ }^{4}$ and poor biodegradation $^{21}$ by activated sludge, the most common process in wastewater treatment. ${ }^{8,22}$ To improve DCF removal, advanced treatment processes were proposed ${ }^{23}$ including sorption by granular active carbon (GAC). ${ }^{21}$ However, it has been reported that the presence of dissolved organic matter (DOM) in many cases reduces the efficiency of GAC to remove micro-organic pollutants. ${ }^{24,25}$ Recently the removal of DCF by micelle-clay composite filters in comparison to GAC filters was reported ${ }^{26}$ but the effect of DOM on the removal was not explored.

We have recently reported the efficient removal of microorganic pollutants from water in the presence of DOM by adsorption to a designed polymer-clay composite. Pyrene adsorption to a poly-4-vinylpyridine-co-styrene (PVPcS)-clay composite was high and increased in the presence of humic acid (HA) which was explained by the high affinity of HA to the composite and a cosorption mechanism. ${ }^{27}$ In contrast, pyrene removal by GAC decreased in the presence of HA. Zedaka et al. $^{28}$ demonstrated the efficient removal of atrazine by protonated PVPcS ( $\mathrm{HPVPcS}$ )-clay composites. Atrazine removal by filtration columns of the composite reached 93-

Received: March 26, 2015

Revised: June 17, 2015

Accepted: June 30, 2015

Published: June 30, 2015 
$96 \%$ and the removal was not compromised in the presence of DOM, whereas GAC filters removed only $75-83 \%$, which decreased in the presence of DOM to $52-68 \%$. The high removal of atrazine was only obtained at low $\mathrm{pHs}$ and at natural pHs atrazine removal dramatically decreased due to deprotonation of the pyridinium groups which compromises the formation of hydrogen bonds between atrazine and the polymer. $^{29}$ Deprotonation at moderate $\mathrm{pHs}$ also reduces the positive charge of $\mathrm{HPVPcS}$, resulting in reduced interactions with anionic pollutants. Since many contaminants such as DCF are anionic at moderate $\mathrm{pHs}$, designing composites based on $\mathrm{PVPcS}$ with a permanent charge (non-pH dependent) would be beneficial.

In the current study we aimed to synthesize a permanently charged novel quaternized poly vinylpyridinium-co-styrene (QPVPcS) in order to design composite sorbents for anionic pollutants. Composites at low and high polymer loadings were characterized by adsorption isotherms, Zeta potential, XRD, FTIR, elements analysis, and TGA and different polymer conformations at the adsorbed state were deduced. The removal of DCF by the composites was investigated and an adsorption mechanism was suggested. The removal of DCF in the presence of HA by filtration with composite columns was compared to the removal by GAC columns.

\section{MATERIALS AND METHODS}

Materials. Wyoming Na-montmorillonite SWy-2 (MMT) was obtained from the Source Clays Repository of the Clay Mineral Society (Columbia, MO); cation exchange capacity (CEC) and specific surface area were 76.4 mequiv/100 $\mathrm{g}$ and $756 \mathrm{~m}^{2} / \mathrm{g}$, respectively. Poly-4-vinylpiridine-co-styrene (PVPcS) (PVP:S ratio 9:1), poly diallyl-dimethylammonium-chloride (PD) (MW 400 000-500 $000 \mathrm{Da}$ ), diclofenac (DCF), methyl iodide (95\%) and humic acid (HA) sodium technical grade were purchased from Sigma-Aldrich. Granular activated carbon (GAC) (Hydraffin 30N, 0.5-2.5 mm, $900 \mathrm{~m}^{2} / \mathrm{g}$ ) was purchased from Benchmark Ltd. (Israel). Quartz sand (grain size $0.8-1.5 \mathrm{~mm}$ ) was purchased from Shoshani \& Weinstein (Israel).

Methods. Polymers Preparation. Quarternization of PVPcS was preformed according to previous studies. ${ }^{30,31}$ PVPcS was freeze-dried, solubilized in $N, N$-dimethylformamude (DMF) for $24 \mathrm{~h}$ and methyl iodide was added in excess ( 1.5 molar ratio). The reaction mixture was refluxed for $12 \mathrm{~h}$ at $60{ }^{\circ} \mathrm{C}$ and was washed thoroughly with hexane. The solvent was removed under reduced pressure and the sample was lyophilized. The quarternization was verified by FTIR and HNMR measurements (Bruker Avance II 500, in DMSO-d6 at $500.2 \mathrm{MHz}$ ). The HNMR spectrum of QPVPcS shows a characteristic signal corresponding to methyl, pyridine and styrene protons (Supporting Information Figure S1). HPVPcS solution was prepared in acidified distilled water (DDW) solution by adding pyridine stoichiometric concentrations of $\mathrm{H}_{2} \mathrm{SO}_{4}$ (95\% purity). PD was dissolved in DDW.

Polymer Adsorption. MMT clay suspension of (0.5\%) was added to QPVPcS $(0.2-3.75 \mathrm{~g} / \mathrm{L}), \mathrm{HPVPcS}(0.2-2 \mathrm{~g} / \mathrm{L})$ or PD ( $1 \mathrm{~g} / \mathrm{L})$ solutions. The clay-polycation suspensions were agitated (for at least $4 \mathrm{~h}$, reaching equilibrium), suspensions were centrifuged $\left(12000 \mathrm{~g}\right.$ for $10 \mathrm{~min}, 18^{\circ} \mathrm{C}$ ) and supernatant was separated. The precipitates were freeze-dried and polymer concentration in supernatant was measured using UV-vis spectrophotometer at a wavelength of 223-226 and 249-256 $\mathrm{nm}$ for QPVPcS and HPVPcS, respectively, and polymer adsorption was calculated. For PD, the percentage of carbon was measured using a CHNSO analyzer (Thermo-Scientific, Fisons, EA1108) and the amount of polymer adsorbed was calculated accordingly.

Composite Characterization. Zeta Potential Measurements. Zeta potentials of MMT, QPVPcS and HPVPcS ( $0.5 \mathrm{~g} /$ L) were measured using a Zetasizer Nanosystem (Malvern Instruments, Southborough, MA). Zeta potential of the composites (0.43-0.83 and 0.69-1.2 $\mathrm{mmol} / \mathrm{g}$ clay for QPVPcS and $\mathrm{HPVPcS}$ composites, respectively) was monitored using composite suspensions ( $0.17 \% \mathrm{MMT})$. Zeta potential of $\mathrm{HPVPcS} / \mathrm{PVPcS}$ composites $(0.8 \mathrm{mmol} / \mathrm{g})$ was measured as a function of $\mathrm{pH}(3-8)$ by adding a concentrated $\mathrm{NaOH}$ solution to the composite suspension and reaching equilibrium.

FTIR Measurements. FTIR spectra were obtained for QPVPcS and QPVPcS composites $(0.43 \mathrm{mmol} / \mathrm{g}$ and 0.83 $\mathrm{mmol} / \mathrm{g})$. Pellets were prepared from dried polymer or composite mixed with $\mathrm{KBr}$ (2:98 ratio). FTIR spectra were recorded at room temperature in the range of $500-4000 \mathrm{~cm}^{-1}$ using a FTIR spectrometer (Nicolet Magna-IR-550, Madiso WI).

X-ray Diffraction (XRD) Measurements. The basal (d 001) spacings of MMT and QPVPcS composite $(0.43-0.83 \mathrm{mmol} / \mathrm{g}$ clay) were measured by XRD. On a round glass slide, $1-2 \mathrm{~mL}$ of the suspension $(0.17 \% \mathrm{MMT})$ were placed and left to sediment (oriented sample) for 1 day. The basal spacing was measured before and after heat treatment at $360^{\circ} \mathrm{C}$ using an $\mathrm{X}$ ray diffractometer (Philips PW1830/3710/3020) with $\mathrm{Cu} \mathrm{KR}$ radiation, $\lambda=1.526 \AA$.

Thermal Measurements. Thermal gravimetric analysis (TGA) of air equilibrated freeze-dried QPVPcS and QPVPcS composites $(0.43-0.83 \mathrm{mmol} / \mathrm{g}$ clay), before and after rinsing the composites with tap water, was carried out by a Q500 termogravimetric Analyzer (TA Instruments Inc.). The high resolution-dynamic program (sensitivity-3, resolution-2) includes a heating rate of $25{ }^{\circ} \mathrm{C} / \mathrm{min}$, temperature ranged from 30 to $800{ }^{\circ} \mathrm{C}$, nitrogen flow rate was $60.0 \mathrm{~mL} / \mathrm{min}$.

Elemental Analysis ( $\mathrm{C}, \mathrm{H}, \mathrm{N}$, and lodide). Determination of $\mathrm{C}, \mathrm{H}$, and $\mathrm{N}$ was performed using the PerkinElmer 2400 series II Analyzer. A combustion method (950-10000 ${ }^{\circ} \mathrm{C}$ ) to convert the sample elements to simple gases was applied. The system uses a steady-state, wavefront chromatographic approach, to separate the controlled gases which are detected as a function of thermal conductivity. Determination of iodide was done using the oxygen-flask combustion method (Schoniger application) for the decomposition of organic samples, and subsequent potentiometric titration by the 835 Titrando Metrohm Titroprocessor and by ion chromatography analysis using a Dionex IC system.

Diclofenac Adsorption to Polymer-Clay Composites. Diclofenac Analysis. DCF (0.05-200 mg/L) was analyzed by HPLC (Agilent Technologies 1200 series) equipped with a diode-array detector. HPLC column was LiChroCARTR 2504 PurospherR STAR RP-18 $(5 \mu \mathrm{m})$, the flow rate was $1.0 \mathrm{~mL} /$ min and detection wavelengths was $276 \mathrm{~nm}$. Measurements were carried out isocratically. A mobile phase of acetonitrile/ acidic water ( $0.1 \%$ formic acid) $80 / 20$ was used. Limit of quantification (LOQ) was $0.05 \mathrm{mg} / \mathrm{L}$.

DCF $(0.025-12 \mu \mathrm{g} / \mathrm{L})$ was measured by LC-MS/MS. The solutions were analyzed by an Agilent 1200 Rapid Resolution LC system (Santa Clara, CA) equipped with an Acclaim C18 RSLC column (Dionex, $2.1 \times 150 \mathrm{~mm}$, particle size $2.2 \mu \mathrm{m}$ ), coupled to a triple quadruple mass spectrometer with an 
electrospray ionization ion source. LC solvents were acidic water $(0.1 \% \mathrm{AcOH})(\mathrm{A})$ and acetonitrile $(0.05 \% \mathrm{AcOH})(\mathrm{B})$. Gradient started from $40 \%$ of A reaching $5 \%$ within 8 min at a flow rate of $0.35 \mathrm{~mL} / \mathrm{min}$, injection volume was $100 \mu \mathrm{L}$. MS was operated in the positive ionization mode. Drying gas (nitrogen) temperature and flow were $350{ }^{\circ} \mathrm{C}$ and $10 \mathrm{~L} / \mathrm{min}$, respectively. Quantitative analysis of DCF was performed in multiple reaction monitoring (MRM) mode, fragmentor potential was $50 \mathrm{~V}$ and MRM transitions were $296 \rightarrow 278$ and $296 \rightarrow 215$. LOD was $0.01 \mu \mathrm{g} / \mathrm{L}$ and LOQ was $0.025 \mu \mathrm{g} /$ L. Isotopically labeled analogue of DCF was used as an internal standard.

Diclofenac Adsorption to QPVPCS Composites. Prior to DCF addition composites were washed by tap water in order to adjust the $\mathrm{pH}$ to $\sim 7$ (for all batch experiments). DCF $(30 \mathrm{mg} /$ $\mathrm{L})$ was added to centrifuge tubes containing QPVPcS composites (0-0.83 mmol polymer/g clay, 0.17\% MMT). The tubes were agitated for $24 \mathrm{~h}$. Supernatants were separated by centrifugation ( $12000 \mathrm{~g}$ for $10 \mathrm{~min}$ ) and prior to HPLC analysis filtered with PTFE syringe filter (AXIVA) $0.45 \mu \mathrm{m}$ pore size. Tests indicated that there was no sorption of DCF by the filters. The experiments were performed in triplicate and samples were kept in darkness in order to avoid photo degradation.

Effect of lonic Strength on DCF Adsorption to PolymerClay Composites. QPVPcS, PVPcS, and PD composites (0.15 $\mathrm{g} / \mathrm{g}, 0.17 \% \mathrm{MMT}$ ) were prepared. The $\mathrm{pH}$ of the suspension was adjusted to $6.5-7$ by rinsing with tap water. DCF $(1 \mathrm{mg} /$ $\mathrm{L})$ was added in the presence of $\mathrm{NaCl}(0-100 \mathrm{mM})$. DCF concentrations in supernatants were measured after $24 \mathrm{~h}$ and its adsorption was calculated.

Diclofenac Humic Acid Interactions. HA solution was filtered under vacuum through a prewashed membrane filter $(0.45 \mu \mathrm{m})$. Total organic carbon (TOC) was measured by TOC analyzer and based on that HA concentration in solution was calculated. ${ }^{32}$ DCF $(100 \mathrm{mg} / \mathrm{L})$ in the presence of HA (1$20 \mathrm{mg} / \mathrm{L})$ and $\mathrm{CaCl}_{2}(10 \mathrm{mM})$ were added to QPVPcS composites $(0.63 \mathrm{mmol} / \mathrm{g}, 1.9 \mathrm{~g} / \mathrm{L})$. Suspensions were agitated for $24 \mathrm{~h}$ and centrifuged $(25000 \mathrm{~g}$ for $15 \mathrm{~min}$ ), DCF concentration in supernatants was measured by HPLC and DCF adsorption was calculated.

Adsorption Isotherms of Diclofenac. QPVPcS composites $(0.63 \mathrm{mmol} / \mathrm{g})$ were prepared as mentioned. DCF $(1-200$ $\mathrm{mg} / \mathrm{L}$ ) was added to centrifuge tubes with suspensions of the composite or GAC $(1.9 \mathrm{~g} / \mathrm{L}$ ) and agitated for $24 \mathrm{~h}$ (equilibrium was reached). DCF concentrations in supernatants were measured by HPLC and DCF adsorption isotherms were constructed. The results were fitted to the Langmuir model using numerical solutions. ${ }^{33}$

Kinetics of Diclofenac Adsorption. Freeze-dried QPVPcS composites $(0.63 \mathrm{mmol} / \mathrm{g})$ and GAC were added to an agitated DCF solution $(2 \mathrm{mg} / \mathrm{L}, 180 \mathrm{~mL})$; final sorbents concentrations were $0.55 \mathrm{~g} / \mathrm{L}$. The concentration of DCF in the suspension was monitored with time $(0-3 \mathrm{~h})$. For each measurement 0.5 $\mathrm{mL}$ were removed from the suspension and analyzed by HPLC.

The kinetics of adsorption was analyzed as follows: ${ }^{34}$

$$
\frac{\mathrm{dCe}}{\mathrm{d} t}=-C \times \mathrm{Ce}(t) \times R(t)+D\left(R_{0}-R(t)\right)
$$

$R_{0}$ is the molar concentration of sorbent surface sites. Kinetic parameters $C\left(\mathrm{M}^{-1} \mathrm{~s}^{-1}\right)$, forward coefficient of adsorption, and $D\left(\mathrm{~s}^{-1}\right)$, rate coefficient of desorption, satisfy the relation $K=$ $C / D\left(R_{0}\right.$ and Kwere determined by the adsorption isotherm).
$R(t)$ denotes the molar concentration of unoccupied sites of the sorbent at time $(t)$. Ce is the contaminant molar concentration, $\mathrm{Ce}(t)$ relates to the contaminant molar concentration at time $(t)$. This set of equations was solved by a Taylor series, as described previously. ${ }^{35}$

Diclofenac and HA Filtration by Composite and GAC Columns. Filtration of Diclofenac Microconcentrations. Experiments were conducted as published previously. ${ }^{27}$ DCF $(1 \mathrm{mg} / \mathrm{L}$ in tap water at $\mathrm{pH}-7.4)$ filtration by columns of QPVPcS and PVPcS composites $(0.15 \pm 0.01 \mathrm{~g} / \mathrm{g})$ and GAC was studied (4 replicates). The flow rate was $2 \mathrm{~mL} / \mathrm{min}, 600$ $\mathrm{mL}$ solution were filtered per column equivalent to 30 pore volumes (PV). Columns were filled with $70 \mathrm{~g}$ sand mixed with $0.7 \mathrm{~g}$ QPVPCS or PVPcS composites $(1: 100 \mathrm{w} / \mathrm{w})$ or with a layer of $0.7 \mathrm{~g}$ of GAC.

The filtration (4L, $200 \mathrm{PV}, 2.3 \mathrm{~mL} / \mathrm{min})$ of DCF $(1 \mathrm{mg} / \mathrm{L}$ in tap water, $\mathrm{pH}-7.4)$ in the presence of $\mathrm{HA}(5 \mathrm{mg} / \mathrm{L})$ by QPVP and GAC columns was measured (two replicates). The columns were prepared with a higher ratio of active sorbent $3.75 \mathrm{~g}$ composite or GAC/sand $(\sim 1: 19 \mathrm{w} / \mathrm{w})$. In both cases the eluting solutions were collected with time and DCF concentrations were determined by HPLC.

Filtration of Diclofenac Nanoconcentrations. DCF (10 $\mu \mathrm{g} / \mathrm{L})$ and $\mathrm{HA}(5 \mathrm{mg} / \mathrm{L})$ filtration $(2 \mathrm{~L}, 100 \mathrm{PV})$ by GAC and QPVPcS composite columns was measured (two replicates). The columns were prepared as described above with active sorbent (composite or GAC) sand ratio of $\sim 1: 19 \mathrm{w} / \mathrm{w}$ and a flow rate of $1.05 \mathrm{~mL} / \mathrm{min}$. DCF concentrations were analyzed by LS-MS/MS.

\section{RESULTS AND DISCUSSION}

Adsorption of QPVPCS and HPVPCS to Montmorillonite. The adsorption isotherms of HPVPcS and of QPVPcS to MMT present similar trends and consist of three stages: linear increase at low polymer concentrations, a plateau and increased adsorption at high polymer concentrations (Supporting Information Figure S2). The adsorption of HPVPcS, at all added concentrations, was higher than the adsorption of QPVPcS, reaching the cation exchange capacity (CEC) of the clay at the plateau region. On the other hand, QPVPcS adsorption reached the CEC only when very high concentrations of the polymer were added. The high adsorption of HPVPcS to MMT can be attributed to the H-bonds formed between HPVPcS and the clay and between the polymer chains ${ }^{36}$ (not relevant in the case of QPVPcS). In addition, the methyl group of QPVPcS may cause steric interference explaining its lower adsorption on the clay. Despite the lower adsorption of QPVPcS to the clay, zeta potentials of the QPVPcS composites are higher than those of the HPVPcS composites, +40 to $+80 \mathrm{vs}+30$ to $+40 \mathrm{mV}$, respectively, advantageous for binding anionic pollutants. These values are in agreement with the zeta potential of the polymers: $+53 \pm 2 \mathrm{mV}$ for QPVPcS and $+20 \pm 2 \mathrm{mV}$ at $\mathrm{pH} 3.2$ for HPVPcS, as $\mathrm{pH}$ increases (above 26.5 ) HPVPcS deprotonates and zeta potential become neutral (results not shown). The positive and neutral zeta potentials of QPVPcS and of HPVPcS (at $\sim \mathrm{pH} 7$ ), respectively, can explain the higher affinity of the anionic DCF to QPVPcS composites. Since QPVPcS composites were found more suitable for DCF removal they were further characterized.

Characterization of QPVPcS-Clay Composites. Enhanced adsorption at high polymer concentrations is usually explained in terms of polymer reorganization on the clay from a 

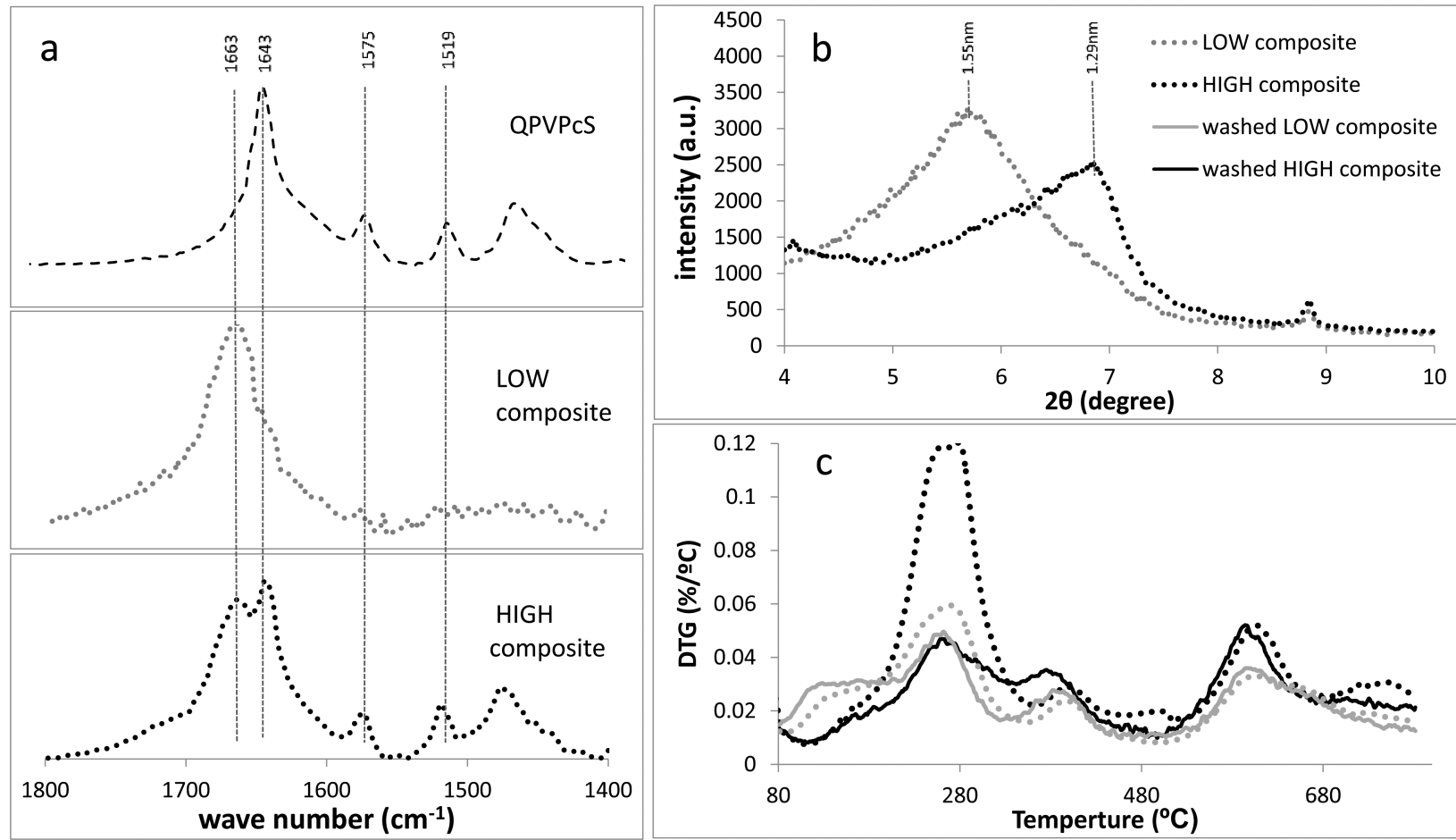

Figure 1. QPVPcS LOW and HIGH composites characterization. (a) FTIR spectra $\left(1800-1400 \mathrm{~cm}^{-1}\right)$. (b) XRD Diffractograms. (c) Differential thermogravimetric analysis profiles before and after washing with tap water.

train configuration into a more extended configuration of loops and tails. ${ }^{3,38}$ To test whether QPVPcS loading on the clay affects its configuration, two QPVPcS composites were further characterized: a low loading composite $(0.41 \mathrm{mmol} / \mathrm{g})$ (denoted LOW) and a composite with a higher loading ( 0.83 $\mathrm{mmol} / \mathrm{g}$ ) (denoted HIGH).

Monitoring the desorption of the counteranion of the adsorbing polycation enables to estimate the degree of polycation exchange. Ion exchange indicates direct contact between the polycation with the clay surface. Complete exchange indicates all polymer segments are "on" the clay in a train configuration, while partial exchange indicates polymer segments also extend into solution (with $\mathrm{I}^{-}$) in a loops configuration. Therefore, upon polycation adsorption the percent of $\mathrm{I}^{-}$(the exchangeable anion of QPVPcS) was measured.

For the LOW composite the iodide/carbon molar ratio was 0.036 while the ratio in the HIGH composite was significantly higher reaching 0.074 . The molar ratio iodide/carbon for the QPVPcS in solution is 0.12 indicating that in the LOW and HIGH composites $\sim 30$ and $62 \%$ of the anion sites are occupied by iodide, respectively. The low percent of iodide in the LOW composite indicates that the polycation adsorbed by ion exchange (desorbing the iodide) adsorbing as trains. The relatively high percent of iodine in the HIGH composite indicates that the polycation adsorbed as trains and as well as loops and tails, retaining the exchangeable anion.

The suggestion that the polymer adsorbs as trains and as loops and tails in addition to trains in the LOW and HIGH composites, respectively, was supported by FTIR measurements of the composites (Figure 1a). Quarternization of PVPcS by methylation of the pyridine was confirmed by the absence of the characteristic pyridine vibrations at 1414 and 1596 $\mathrm{cm}^{-139,40}$ in the QPVPcS sample and appearance of the three characteristic peaks of pyridinium at $1519,1575,1643 \mathrm{~cm}^{-1} .41$
The shift from 1596 to $1643 \mathrm{~cm}^{-1}$ is assigned to pyridinium ${ }^{42}$ (1637 and $1643 \mathrm{~cm}^{-1}$ for HPVPcS and QPVPcS respectively). The intensities of the vibrations 1519 and $1575 \mathrm{~cm}^{-1}$ obtained from the composites were in agreement with polymer loading. Upon QPVPcS adsorption a red shift of the $1643 \mathrm{~cm}^{-1}$ vibration to $1663 \mathrm{~cm}^{-1}$ was measured which may be attributed to the formation of electrostatic interactions between the pyridinium and the negatively charged clay surface. A major shift to $1663 \mathrm{~cm}^{-1}$ was observed for the LOW composite while both vibrations, 1643 and at $1663 \mathrm{~cm}^{-1}$, were recorded for the $\mathrm{HIGH}$ composite indicating that at high polymer loading a fraction of the adsorbed QPVPcS does not interact directly with the clay. This supports our suggestion that in the LOW composite the polymer mainly adsorbs as trains whereas at high polymer loadings a polymer configuration of loops and tails occurs as well.

Furthermore, the HIGH composite reached a very positive zeta potential of $80 \mathrm{mV}$ which is in agreement with the high QPVPcS loading exceeding the CEC of MMT. For the LOW composite, although QPVPcS adsorption is below the CEC zeta potential reached a positive value, $45 \mathrm{mV}$. We have reported that positive values of zeta potential may be reached at polycation loadings below the CEC due to screening of the clay surface by the highly charged polycation. ${ }^{43}$ In addition, at polymer loadings below the CEC, polymer intercalation is probably not complete, that is, internal exchangeable sites may be unoccupied, but all external sites are associated with the adsorbed polymer resulting in a positive zeta potential.

To test whether the polycation intercalates the clay platelets $\mathrm{X}$-ray diffractograms of the two composites and MMT before and after heat treatment $\left(360{ }^{\circ} \mathrm{C}\right)$ were obtained (Figure $1 \mathrm{~b}$ and Supporting Information Figure S3). The basal spacing of MMT, with one water layer, is $1.24 \mathrm{~nm}$. For the LOW composite the spacing increased to $1.55 \mathrm{~nm}$ but for the HIGH composite it only increased to $1.29 \mathrm{~nm}$. Upon heating the 
spacing of MMT is $0.97 \mathrm{~nm}$, whereas for both composites a spacing of $1.34^{+1} \mathrm{~nm}$ was reached indicating polymer intercalation.

For the HIGH composite the peak is broad and nonsymmetric with a shoulder $(1.5 \mathrm{~nm})$ and partial exfoliation (at low angles) is observed. Such a pattern is recorded for composites with heterogeneous intercalation/exfoliation. The decrease of the basal spacing with an increase in polymer loading may be attributed to water exclusion upon high polymer intercalation, suggesting that in the case of the LOW composite both water and polymer are intercalated. A similar effect of water inclusion/exclusion on the d-space of composites has been described for methylene blue-clay composites. $^{44}$ The d-space similarity upon heating can be attributed to water exclusion for LOW composite and reorganization in more extended configuration for the HIGH composite. Serratosa ${ }^{45}$ reported that upon an increase in pyridine monomer adsorption, a decrease in the basal spacing was obtained due to a shift from perpendicular to parallel orientation. Such a shift is less probable to occur for polymer adsorption.

The suggestion that polymer intercalation in the HIGH composite includes water exclusion is supported by derivative thermogravimetric (DTG) measurements of MMT and of the composites (Figure 1c). For MMT weight loss was obtained at 60 and $674{ }^{\circ} \mathrm{C}$ which is attributed to hygroscopic water and dehydration of structural water, respectively. ${ }^{46,47}$ For the LOW composite an additional weight loss at $\sim 105{ }^{\circ} \mathrm{C}$, attributed to water, is recorded supporting the conclusion that water is intercalated in the LOW composite.

QPVPcS polymer exhibited two discrete weight loss temperatures at 268 and $310{ }^{\circ} \mathrm{C}$ (Supporting Information Figure S4). For both composites weight loss of the polymer was recorded at $\sim 260{ }^{\circ} \mathrm{C}$ (similar to the nonadsorbed polymer) and at higher temperatures of 380 and $600{ }^{\circ} \mathrm{C}$. Thermal stability of organic molecules upon adsorption to MMT, that is, shift of polymer, surfactant and intercalated organic compounds onset temperature to higher temperatures in the composite, has been thoroughly reported and discussed. ${ }^{48,49}$

The extremely high shift to an onset of $600{ }^{\circ} \mathrm{C}$ could be attributed to highly stable intercalated QPVPcS. The main difference obtained from the DTG between the two composites is that for the washed HIGH composite a decrease in the peak at $260-280{ }^{\circ} \mathrm{C}$ was observed. Conceivably, a fraction of the high loading is less thermo-stable, polymer was loosely associated with the clay resulting in polymer desorption.

Finally, based on the zeta potential, TGA, XRD, FTIR, and iodide/carbon measurements of the LOW and HIGH composites, a nanostructure of polymer configuration on MMT surface was suggested (Figure 2). In the LOW composite, QPVPcS adsorbed to the external surface in a train configuration and its intercalation was accompanied by water. In contrast, for the HIGH composite polymer intercalated without water, its adsorption at the clay surface was as trains but also in a configuration of loops and tails and a fraction of the adsorbed polymer was loosely associated with the clay resulting in its desorption upon composite rinsing. Indeed, the desorption increases with an increase in polymer adsorption. At low polycation loadings, polymer desorption is negligible. However, some desorption was obtained in the case of the HIGH composite. Despite QPVPcS desorption DCF removal was not compromised (see below).
MMT

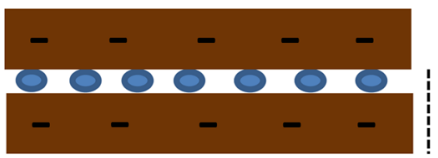

$1.24 \mathrm{~nm}$

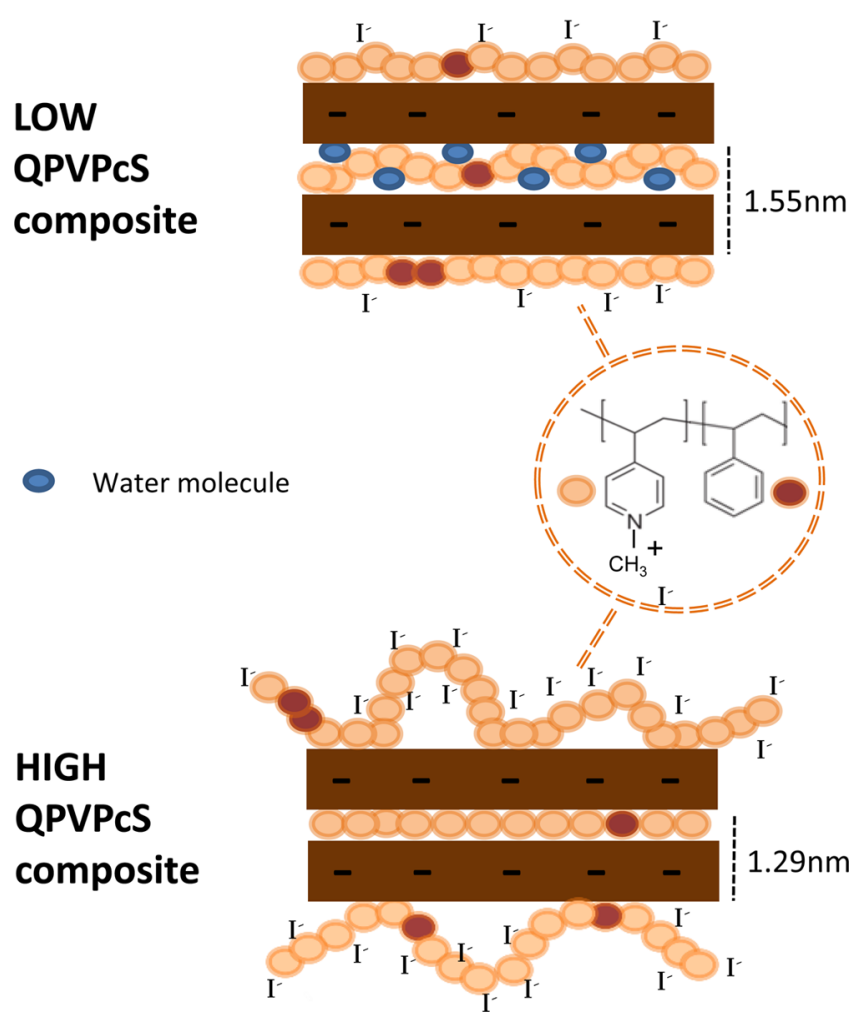

Figure 2. Schematic representation of QPVPcS composites conformation at low and high loading.

Diclofenac Adsorption to QPVPcS Composites. The efficiency of DCF adsorption to QPVPcS composites increased with polymer loading in the composite (Supporting Information Figure S5). DCF adsorption reached a plateau with nearly complete DCF adsorption at a polymer loading of $0.63 \mathrm{mmol} /$ g, similar to the HIGH composite. The interactions between DCF and the HIGH QPVPcS composite were further explored.

The interaction between DCF and the adsorbed QPVPcS could be based on electrostatic, van der Waals, $\pi-\pi$ and hydrophobic interactions. To test the significance of electrostatic interactions the effect of ionic strength on DCF adsorption to the QPVPcS composite was tested. Results were compared to a composite that mainly forms electrostatic interactions, PD-MMT, and to a composite for which electrostatic interactions are minor, PVPcS-MMT (Figure 3). Indeed the adsorption of DCF to the PD composite decreased dramatically as the ionic strength increased due to screening of the electrostatic interaction. On the other hand, DCF interaction with the PVPcS composite were high and hardly affected by the increase in the ionic strength, indicating that noncoloumbic bonds, such as H-bonds, $\pi-\pi$ and hydrophobic interactions, dominate DCF PVPcS interactions. The increase in ionic strength slightly decreased DCF adsorption to the QPVPcS composite but even at high ionic strengths the adsorption remained high suggesting that not only electrostatic interaction dominate the adsorption but also noncoloumbic bonds. At a higher DCF/composites ratio (DCF $2 \mathrm{mg} / \mathrm{L}$, 


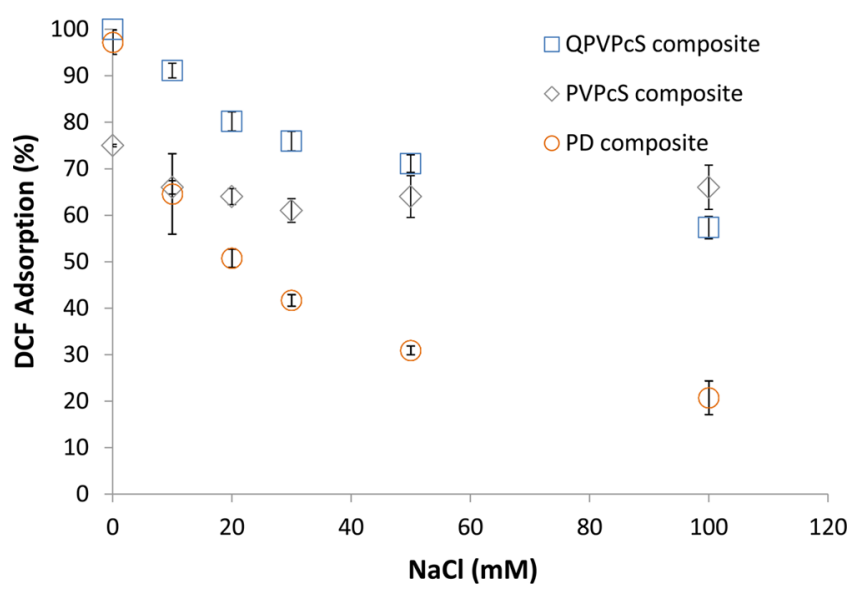

Figure 3. DCF $(1 \mathrm{mg} / \mathrm{L})$ adsorption to $\mathrm{PD}, \mathrm{QPVPcS}$ and PVPcS composites $(0.15 \pm 0.01 \mathrm{~g} / \mathrm{g})$ as a function of $\mathrm{NaCl}$ concentration (0$100 \mathrm{mM})$.

composites $0.55 \mathrm{~g} / \mathrm{L}, 0.15 \mathrm{~g} / \mathrm{g}$ ) (not shown), DCF adsorption to a QPVPcS composite was 3-fold higher than to a PVPcS composite. Hence, we can conclude that electrostatic interactions along with more specific ones promote DCF removal by QPVPcS composites.

To determine the capacity of the QPVPcS composite and of GAC to adsorb DCF, adsorption isotherms were constructed and Langmuir coefficients were calculated (Supporting Information Figure S6 and Table 1). The adsorption capacities ( $Q_{\max }$ coefficient) and the binding coefficients $(K)$ to the composite and to GAC were in the same order of magnitude. The adsorption capacity to the QPVPcS composite was somewhat higher than to GAC, whereas the binding coefficient was slightly higher to GAC than to the composite. The adsorption capacity of the QPVPcS composite is higher or similar to other sorbents such as Cetylpyridinium-zeolite ${ }^{50}$ and $\mathrm{CNts}_{\text {alumina }}{ }^{51}$ or hybrid poloxamer-MMT ${ }^{52}$ respectively. Nir et al. (2014) studied the adsorption of DCF to ODTMAMMT composites and reported a high capacity but the binding affinity coefficient $(\mathrm{K})$ was lower than reported for the QPVPcS composite. However, the main advantage of the QPVPcS composite is not only its high capacity and binding affinity but rather the high removal of DCF in the presence of humic substances (see below).

Although the equilibrium isotherms were similar for QPVPcS composite and GAC, the adsorption rate of DCF to the composite was significantly faster (Figure 4). While DCF removal by GAC was reached only $53 \%$ after $3 \mathrm{~h}$, the removal by the composite was complete within $45 \mathrm{~min}$.

The binding affinity coefficient $(K)$ can be described by the adsorption $(C)$ and desorption $(D)$ coefficients, $K=C / D$ which can be calculated from the kinetic time dependent Langmuir equation. By relating this equation to the kinetic results, $\mathrm{C}$ and $\mathrm{D}$ can be quantitatively determined (Table 1 ).

The kinetic adsorption coefficient $(C)$ of DCF to QPVPcS composite is a magnitude higher than to GAC. On the other

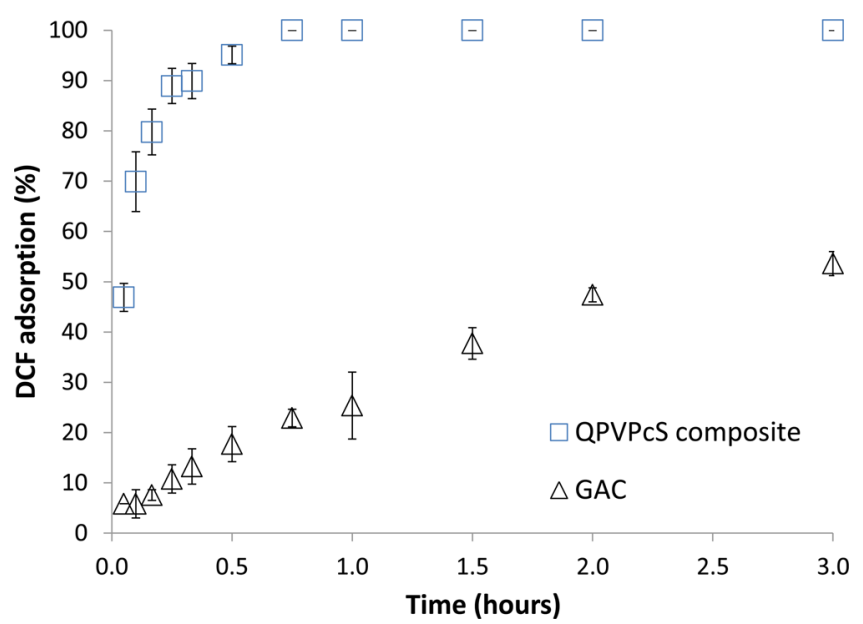

Figure 4. Kinetics of DCF $(2 \mathrm{mg} / \mathrm{L})$ adsorption on QPVPcS composite $(0.63 \mathrm{mmol} / \mathrm{g})$ and GAC $(0.55 \mathrm{~g} / \mathrm{L})$.

hand, the release coefficient (D) of DCF from GAC is significantly lower. The kinetic adsorption coefficient is a dominant parameter in the first stages of filtration. Since $Q_{\max }$ values of the sorbents are similar and the adsorption of DCF to the composite is faster than to GAC efficient removal of DCF by filtration with composite columns is expected.

Diclofenac Filtration by Composite and GAC Columns. Diclofenac Removal by Filtration with QPVPCS and PVPCS Composites and GAC Columns. The removal of DCF $(1 \mathrm{mg} / \mathrm{L}, \mathrm{pH} 7.4)$ by filtration with GAC, QPVPcS, and PVPcS composite columns was tested (Supporting Information Figure S7). DCF removal by the PVPcS composite column was not efficient due to deprotonation of the composite at the $\mathrm{pH}$ of tap water. The GAC column showed relatively low affinity to DCF (55\%), but removal stayed constant throughout the experiment. On the other hand, DCF removal by the QPVPcS composite column was complete for up to 10 pore volumes followed by a linear decrease. These trends correlate to the values calculated for the adsorption $(C)$ and desorption $(D)$ coefficients, that is, high and low for the composite and GAC, respectively.

DCF filtration ( $1 \mathrm{mg} / \mathrm{L}, \mathrm{pH} 7.4)$ by composite columns was higher than by GAC columns (for the first $40 \mathrm{PV}$ ) and not reduced in the presence of $\mathrm{HA}(5 \mathrm{mg} / \mathrm{L})$, whereas its filtration by GAC was significantly compromised in the presence of HA (reduced to $76 \%$ from 93\%) (Figure 5a and b). High efficiency of DCF removal by columns of QPVPcS composite was demonstrated despite desorption of QPVPcS from the column (desorption was completed after 15 PV). Further studies addressing the stability of QPVPcS-clay composites may include, exploring the effect of decreasing QPVPcS charge density (less methylation) or increasing the preparation solution ionic strength, which should both increase composite stability.

The reduction in micropollutant removal by GAC in the presence of DOM has been explained in terms of pore

Table 1. Coefficients for Equilibrium $\left(Q_{\max }, K\right)$ and for Kinetic (C-Adsorption, D-Desorption) Isotherm for QPVPcS Composite and GAC

$\begin{array}{lccccc} & Q_{\max }(\mathrm{mol} / \mathrm{g}) & K(\mathrm{~L} / \mathrm{mol}) & C(\mathrm{~L} / \mathrm{min} \cdot \mathrm{mol}) & D(1 / \mathrm{min}) & R^{2} \\ \text { GAC } & 2.8 \times 10^{-4} & 3.8 \times 10^{4} & 11 & 2.8 \times 10^{-4} & 9.5 \times 10^{-1} \\ \text { QPVPcS composite } & 3.4 \times 10^{-4} & 2.6 \times 10^{4} & 2.5 \times 10^{2} & 9.4 \times 10^{-3} & 9.3 \times 10^{-1}\end{array}$




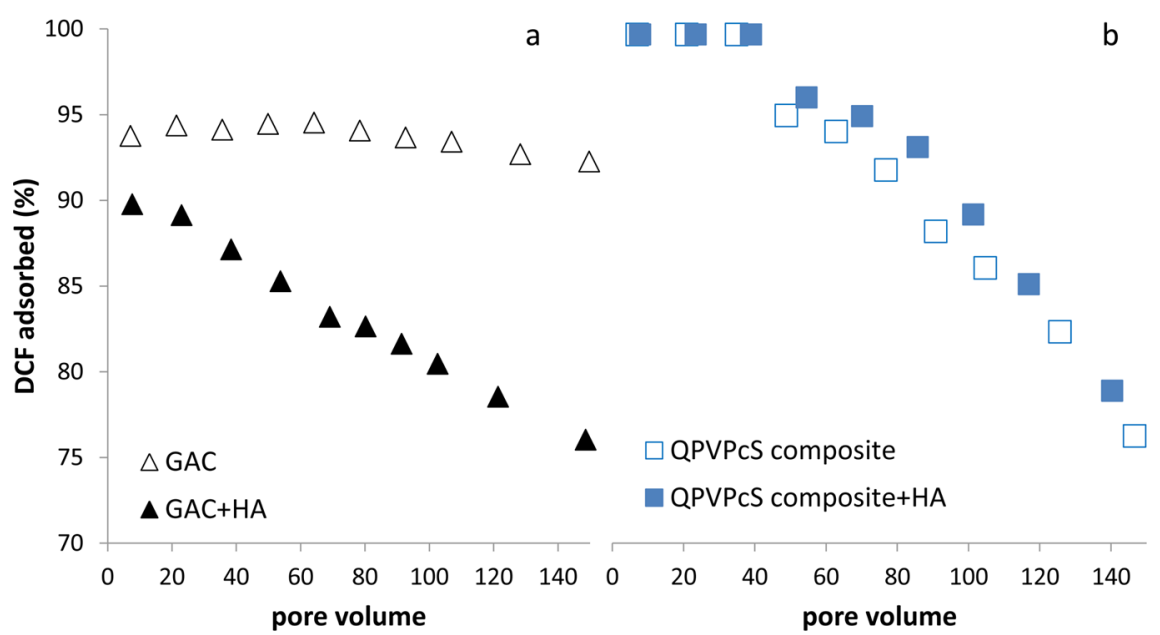

Figure 5. Effect HA ( $5 \mathrm{mg} / \mathrm{L})$ on DCF $(1 \mathrm{mg} / \mathrm{L})$ removal by columns of GAC (a) and QPVPcS composites $(0.63 \mathrm{mmol} / \mathrm{g})(\mathrm{b})$, flow rate $2.3 \mathrm{~mL} /$ min standard deviations were $0.1-6.3 \%$ and $0-8.1 \%$ for GAC and QPVPcS composite, respectively.

clogging $^{53}$ which is not a limitation in the case of the composite. Indeed, not only in filtration, but also in suspension, the presence of HA $(1-20 \mathrm{mg} / \mathrm{L})$ did not affect the removal of DCF $(100 \mathrm{mg} / \mathrm{L})$ by the QPVPcS composite $(1.9 \mathrm{~g} / \mathrm{L})$ which reached $33 \pm 2 \mathrm{mg} / \mathrm{g}$ in all cases (results not shown). The adsorption of HA and DCF on composite surfaces can be affected in three main mechanisms: 1. Co-adsorption. 2. Competition. 3. Independently. Since DCF and HA are both anionic (at natural $\mathrm{pHs}$ ) strong interactions between the two are not expected, excluding coadsorption. Both filtration and batch results suggest that HA and DCF do not compete on the same adsorption sites on the composite,that is, the adsorption may be independently. More research must be conducted in order to establish a complete understanding.

DCF filtration at nanoconcentration $(10 \mu \mathrm{g} / \mathrm{L})$ in the presence of HA $(5 \mathrm{mg} / \mathrm{L})$ by GAC and QPVPcS composites was measured (Table 2$)$. Throughout the experiment $(\sim 100$

Table 2. DCF $(10 \mu \mathrm{g} / \mathrm{L})$ Removal in the Presence of HA (5 $\mathrm{mg} / \mathrm{L})$ by Columns of QPVPcS Composites $(0.63 \mathrm{mmol} / \mathrm{g}$ ) and GAC Mixed with Sand (1/19), Flow Rate $1.05 \pm 0.1$ $\mathrm{mL} / \mathrm{min}$

\begin{tabular}{ccc} 
& \multicolumn{2}{c}{$C / C_{0}$} \\
\cline { 2 - 3 } pore volumes & QPVPcS composite & GAC \\
18 & $5.0 \times 10^{-3}$ & $6.0 \times 10^{-3}$ \\
26 & $4.0 \times 10^{-3}$ & $8.0 \times 10^{-3}$ \\
33 & $5.0 \times 10^{-3}$ & $11 \times 10^{-3}$ \\
40 & $5.0 \times 10^{-3}$ & $13 \times 10^{-3}$ \\
48 & $5.0 \times 10^{-3}$ & $16 \times 10^{-3}$ \\
73 & $12 \times 10^{-3}$ & $35 \times 10^{-3}$ \\
103 & $26 \times 10^{-3}$ & $43 \times 10^{-3}$ \\
\hline
\end{tabular}

pore volumes) the removal of DCF by the composite columns was higher than by the GAC columns. At the end of the experiment DCF concentration eluting from the GAC column was 2-fold higher than the concentration eluting from the composite columns emphasizing the advantage of the composite as a sorbent. A better understanding of the DOM-composite interactions may explain the high adsorption of DCF by the composite even in the presence of high DOM concentrations.
The removal of DCF by the QPVPcS composite was advantageous since it was efficient and not reduced at high ionic strength or in the presence of HA (common in surfaceand wastewater). In contrast, the performance of most commercial sorbets, such as GAC, is compromised under such conditions. In addition, DCF removal by QPVPcS composite was faster than by GAC which is crucial in upscale filtration. Further studies may address the suitability of the composite to remove additional acidic micropollutants and the regeneration of the composite filters.

\section{ASSOCIATED CONTENT}

\section{S Supporting Information}

Supplementary figures (S1-S7). H NMR spectrum of QPVPcS (S1). Zeta Potential and adsorption isotherms of HPVPcS and QPVPcS on MMT (S2). XRD diffractograms of QPCPcS LOW and HIGH composites and MMT after heat treatment (S3). TGA profiles of QPVPcS polymer (S4). DCF adsorption on QPVPcS composites (S5). DCF adsorption isotherm on QPVPcS composite and GAC (S6) and DCF filtration by HPVPcS- QPVPcS- composites and GAC (S7).The Supporting Information is available free of charge on the ACS Publications website at DOI: 10.1021/acs.est.5b01530.

\section{AUTHOR INFORMATION}

\section{Corresponding Author}

*Phone: 972-8-948-9171; fax: 972-8-948-9856; e-mail: yael. mishael@mail.huji.ac.il.

\section{Notes}

The authors declare no competing financial interest.

\section{ACKNOWLEDGMENTS}

This research was supported by BSF, The United States-Israel Binational Science Foundation (grant 2010438) and by the Israeli Ministry of Trade and Industry, Kamin Project (grant 54914).

\section{REFERENCES}

(1) Kolpin, D. W.; Furlong, E. T.; Meyer, M. T.; Thurman, E. M.; Zaugg, S. D.; Barber, L. B.; Buxton, H. T. Pharmaceuticals, Hormones, and Other Organic Wastewater Contaminants in U.S. Streams, 19992000: A National Reconnaissance. Environ. Sci. Technol. 2002, 36, $1202-1211$. 
(2) Clara, M.; Strenn, B.; Gans, O.; Martinez, E.; Kreuzinger, N.; Kroiss, H. Removal of selected pharmaceuticals, fragrances and endocrine disrupting compounds in a membrane bioreactor and conventional wastewater treatment plants. Water Res. 2005, 39, 47974807.

(3) Jelic, A.; Gros, M.; Ginebreda, A.; Cespedes-Sánchez, R.; Ventura, F.; Petrovic, M.; Barcelo, D. Occurrence, partition and removal of pharmaceuticals in sewage water and sludge during wastewater treatment. Water Res. 2011, 45, 1165-1176.

(4) Nikolaou, A.; Meric, S.; Fatta, D. Occurrence patterns of pharmaceuticals in water and wastewater environments. Anal. Bioanal. Chem. 2007, 387, 1225-1234.

(5) Mompelat, S.; Le Bot, B.; Thomas, O. Occurrence and fate of pharmaceutical products and by-products, from resource to drinking water. Environ. Int. 2009, 35, 803-814.

(6) Goldstein, M.; Shenker, M.; Chefetz, B. Insights into the uptake processes of wastewater-borne pharmaceuticals by vegetables. Environ. Sci. Technol. 2014, 48, 5593-5600.

(7) Malchi, T.; Maor, Y.; Tadmor, G.; Shenker, M.; Chefetz, B. Irrigation of root vegetables with treated wastewater: evaluating uptake of pharmaceuticals and the associated human health risks. Environ. Sci. Technol. 2014, 48, 9325-9333.

(8) Zhang, Y.; Geissen, S.-U.; Gal, C. Carbamazepine and diclofenac: Removal in wastewater treatment plants and occurrence in water bodies. Chemosphere 2008, 73, 1151-1161.

(9) Vieno, N.; Sillanpää, M. Fate of diclofenac in municipal wastewater treatment plant - a review. Environ. Int. 2014, 69, 28-39.

(10) Verlicchi, P.; Al Aukidy, M.; Zambello, E. Occurrence of pharmaceutical compounds in urban wastewater: removal, mass load and environmental risk after a secondary treatment-a review. Sci. Total Environ. 2012, 429, 123-155.

(11) Hernando, M. D.; Heath, E.; Petrovic, M.; Barceló, D. Tracelevel determination of pharmaceutical residues by LC-MS/MS in natural and treated waters. A pilot-survey study. Anal. Bioanal. Chem. 2006, 385, 985-991.

(12) Kim, S. D.; Cho, J.; Kim, I. S.; Vanderford, B. J.; Snyder, S. A. Occurrence and removal of pharmaceuticals and endocrine disruptors in South Korean surface, drinking, and waste waters. Water Res. 2007, 41, 1013-1021.

(13) Kosjek, T.; Heath, E.; Pérez, S.; Petrović, M.; Barceló, D. Metabolism studies of diclofenac and clofibric acid in activated sludge bioreactors using liquid chromatography with quadrupole - time-offlight mass spectrometry. J. Hydrol. 2009, 372, 109-117.

(14) Triebskorn, R.; Casper, H.; Heyd, A.; Eikemper, R.; Köhler, H.R.; Schwaiger, J. Toxic effects of the non-steroidal anti-inflammatory drug diclofenac. Part II: cytological effects in liver, kidney, gills and intestine of rainbow trout (Oncorhynchus mykiss). Aquat. Toxicol. 2004, 68, 151-166.

(15) Triebskorn, R.; Casper, H.; Scheil, V.; Schwaiger, J. Ultrastructural effects of pharmaceuticals (carbamazepine, clofibric acid, metoprolol, diclofenac) in rainbow trout (Oncorhynchus mykiss) and common carp (Cyprinus carpio). Anal. Bioanal. Chem. 2007, 387, $1405-1416$.

(16) Eades, C.; Waring, C. P. The effects of diclofenac on the physiology of the green shore crab Carcinus maenas. Mar. Environ. Res. 2010, 69 (Suppl), S46-S48.

(17) Nassef, M.; Kim, S. G.; Seki, M.; Kang, I. J.; Hano, T.; Shimasaki, Y.; Oshima, Y. In ovo nanoinjection of triclosan, diclofenac and carbamazepine affects embryonic development of medaka fish (Oryzias latipes). Chemosphere 2010, 79, 966-973.

(18) Kallio, J.-M.; Lahti, M.; Oikari, A.; Kronberg, L. Metabolites of the aquatic pollutant diclofenac in fish bile. Environ. Sci. Technol. 2010, 44, 7213-7219.

(19) Brozinski, J.-M.; Lahti, M.; Meierjohann, A.; Oikari, A.; Kronberg, L. The anti-inflammatory drugs diclofenac, naproxen and ibuprofen are found in the bile of wild fish caught downstream of a wastewater treatment plant. Environ. Sci. Technol. 2013, 47, 342-348.

(20) Schwaiger, J.; Ferling, H.; Mallow, U.; Wintermayr, H.; Negele, R. D. Toxic effects of the non-steroidal anti-inflammatory drug diclofenac. Part I: histopathological alterations and bioaccumulation in rainbow trout. Aquat. Toxicol. 2004, 68, 141-150.

(21) Ternes, T. A.; Meisenheimer, M.; McDowell, D.; Sacher, F.; Brauch, H.-J.; Haist-Gulde, B.; Preuss, G.; Wilme, U.; Zulei-Seibert, N. Removal of Pharmaceuticals during Drinking Water Treatment. Environ. Sci. Technol. 2002, 36, 3855-3863.

(22) Joss, A.; Keller, E.; Alder, A. C.; Göbel, A.; McArdell, C. S.; Ternes, T.; Siegrist, H. Removal of pharmaceuticals and fragrances in biological wastewater treatment. Water Res. 2005, 39, 3139-3152.

(23) Ziylan, A.; Ince, N. H. The occurrence and fate of antiinflammatory and analgesic pharmaceuticals in sewage and fresh water: treatability by conventional and non-conventional processes. J. Hazard. Mater. 2011, 187, 24-36.

(24) Ernst, M. Characterization of the DOC in nanofiltration permeates of a tertiary effluent. Water Res. 2000, 34, 2879-2886.

(25) Zadaka, D.; Nir, S.; Radian, A.; Mishael, Y. G. Atrazine removal from water by polycation-clay composites: effect of dissolved organic matter and comparison to activated carbon. Water Res. 2009, 43, 677683.

(26) Karaman, R.; Khamis, M.; Quried, M.; Halabieh, R.; Makharzeh, I.; Manassra, A.; Abbadi, J.; Qtait, A.; Bufo, S. A.; Nasser, A.; et al. Removal of diclofenac potassium from wastewater using clay-micelle complex. Environ. Technol. 2012, 33, 1279-1287.

(27) Radian, A.; Mishael, Y. Effect of humic acid on pyrene removal from water by polycation-clay mineral composites and activated carbon. Environ. Sci. Technol. 2012, 46, 6228-6235.

(28) Zadaka, D.; Nir, S.; Radian, A.; Mishael, Y. G. Atrazine removal from water by polycation-clay composites: Effect of dissolved organic matter and comparison to activated carbon. Water Res. 2009, 43, 677683.

(29) Gardi, I.; Nir, S.; Mishael, Y. G. Filtration of triazine herbicides by polymer-clay sorbents: Coupling an experimental mechanistic approach with empirical modeling. Water Res. 2015, 70C, 64-73.

(30) Ishizu, K.; Kashi, Y.; Fukutomi, T.; Kakurai, T. Synthesis of AB and $\mathrm{BAB}$ poly(styrene-b-4-vinylpyridine) and solution properties of their quaternized compounds. Makromol. Chem. 1982, 183, 30993107.

(31) Poly(styrene-b- N-methyl 4-vinyl pyridine iodide) procedure http://www.polymersource.com/dataSheet/P3192-S4VPQ.pdf (accessed January 28, 2015).

(32) Kam, S. The interaction of humic substances with cationic polyelectrolytes. Water Res. 2001, 35, 3557-3566.

(33) Nir, S.; Undabeytia, T.; Yaron-Marcovich, D.; El-Nahhal, Y.; Polubesova, T.; Serban, C.; Rytwo, G.; Lagaly, G.; Rubin, B. Optimization of Adsorption of Hydrophobic Herbicides on Montmorillonite Preadsorbed by Monovalent Organic Cations: interaction between Phenyl Rings. Environ. Sci. Technol. 2000, 34, 1269-1274.

(34) Undabeytia, T.; Nir, S.; Sánchez-Verdejo, T.; Villaverde, J.; Maqueda, C.; Morillo, E. A clay-vesicle system for water purification from organic pollutants. Water Res. 2008, 42, 1211-1219.

(35) Nir, S.; Peled, R.; Lee, K.-D. Analysis of particle uptake by cells: Binding to several receptors, equilibration time, endocytosis. Colloids Surf., A 1994, 89, 45-57.

(36) Farmer, V. C.; Mortland, M. M. An infrared study of the coordination of pyridine and water to exchangeable cations in montmorillonite and saponite. J. Chem. Soc. A 1966, 344.

(37) Breen, C. The characterisation and use of polycation-exchanged bentonites. Appl. Clay Sci. 1999, 15, 187-219.

(38) Theng, B. K. G. Clay-polymer interactions; summary and perspectives. Clays Clay Miner. 1982, 30, 1-10.

(39) Li, G.; Shen, J.; Zhu, Y. A study of pyridinium-type functional polymers. I. Preparation and characterization of soluble pyridiniumtype functional polymers. J. Appl. Polym. Sci. 1996, 62, 2247-2255.

(40) Zhang, H.; Wang, Z.; Zhang, Y.; Zhang, X. Hydrogen-bondingdirected layer-by-layer assembly of poly(4-vinylpyridine) and poly(4vinylphenol): effect of solvent composition on multilayer buildup. Langmuir 2004, 20, 9366-9370.

(41) Singh, P. K.; Bhattacharya, B.; Nagarale, R. K.; Pandey, S. P.; Kim, K.-W.; Rhee, H.-W. Ionic liquid doped poly(N-methyl 4- 
vinylpyridine iodide) solid polymer electrolyte for dye-sensitized solar cell. Synth. Met. 2010, 160, 950-954.

(42) Fournaris, K. G.; Karakassides, M. A.; Petridis, D.; Yiannakopoulou, K. Clays Polyvinylpyridine Nanocomposites. Chem. Mater. 1999, 11, 2372-2381.

(43) Radian, A.; Mishael, Y. G. Characterizing and designing polycation - Clay nanocomposites as a basis for imazapyr controlled release formulations. Environ. Sci. Technol. 2008, 42, 1511-1516.

(44) Rytwo, G.; Nir, S.; Margulies, L. Interactions of Monovalent Organic Cations with Montmorillonite: Adsorption Studies and Model Calculations. Soil Science Society of America Journal 1995, 59, 554.

(45) SERRATOSA, J. M. Use of Infra-red Spectroscopy to determine the Orientation of Pyridine sorbed on Montmorillonite. Nature 1965, 208, 679-681.

(46) Joshi, G. V.; Kevadiya, B. D.; Mody, H. M.; Bajaj, H. C. Confinement and controlled release of quinine on chitosanmontmorillonite bionanocomposites. J. Polym. Sci., Part A: Polym. Chem. 2012, 50, 423-430.

(47) Lin, F. H.; Lee, Y. H.; Jian, C. H.; Wong, J.-M.; Shieh, M.-J.; Wang, C.-Y. A study of purified montmorillonite intercalated with 5fluorouracil as drug carrier. Biomaterials 2002, 23, 1981-1987.

(48) Park, Y.; Ayoko, G. A.; Frost, R. L. Characterisation of organoclays and adsorption of p-nitrophenol: environmental application. J. Colloid Interface Sci. 2011, 360, 440-456.

(49) Noh, M. W.; Lee, D. C. Synthesis and characterization of PSclay nanocomposite by emulsion polymerization. Polym. Bull. 1999, 42, 619-626.

(50) Krajišnik, D.; Daković, A.; Milojević, M.; Malenović, A.; Kragović, M.; Bogdanović, D. B.; Dondur, V.; Milić, J. Properties of diclofenac sodium sorption onto natural zeolite modified with cetylpyridinium chloride. Colloids Surf., B 2011, 83, 165-172.

(51) Wei, H.; Deng, S.; Huang, Q.; Nie, Y.; Wang, B.; Huang, J.; Yu, G. Regenerable granular carbon nanotubes/alumina hybrid adsorbents for diclofenac sodium and carbamazepine removal from aqueous solution. Water Res. 2013, 47, 4139-4147.

(52) Kahur, M.; Datta, M. In vitro releaseof sodium diclofenac from poloxamer 188 modified monmorillonite as an oral drug delivery vehicle. Int. J. Pharm. Pharm. Sci. 2014, 6.

(53) Ding, L.; Snoeyink, V. L.; Mariñas, B. J.; Yue, Z.; Economy, J. Effects of Powdered Activated Carbon Pore Size Distribution on the Competitive Adsorption of Aqueous Atrazine and Natural Organic Matter. Environ. Sci. Technol. 2008, 42, 1227-1231. 